\title{
DNA vaccine constructs against enterovirus 7 I elicit immune response in mice
}

\author{
Wong Siew Tung 1 , Sazaly Abu Bakar ${ }^{2}$, Zamberi Sekawi ${ }^{3}$ and Rozita Rosli*1
}

Address: ${ }^{1}$ Dept. of Human Growth and Development, Faculty of Medicine and Health Sciences, Universiti Putra Malaysia, 43400 Serdang, Selangor, Malaysia, ${ }^{2}$ Department of Medical Microbiology, Faculty of Medicine, Universiti Malaya Medical Center, 50603 Kuala Lumpur, Malaysia and ${ }^{3}$ Dept of Clinical Laboratory Sciences, Faculty of Medicine and Health Sciences, Universiti Putra Malaysia, 43400 Serdang, Selangor, Malaysia

Email: Wong Siew Tung - siewtung77@hotmail.com; Sazaly Abu Bakar - sazaly@ummc.edu.my;

Zamberi Sekawi - zamberi@medic.upm.edu.my; Rozita Rosli* - rozita@medic.upm.edu.my

* Corresponding author

Published: 19 April 2007

Genetic Vaccines and Therapy 2007, 5:6 doi:10.1186/1479-0556-5-6

This article is available from: http://www.gvt-journal.com/content/5/I/6

(c) 2007 Tung et al; licensee BioMed Central Ltd.

This is an Open Access article distributed under the terms of the Creative Commons Attribution License (http://creativecommons.org/licenses/by/2.0), which permits unrestricted use, distribution, and reproduction in any medium, provided the original work is properly cited.

\begin{abstract}
Background: Enterovirus 7I (EV7I) is a major causative viral agent responsible for large outbreaks of hand, foot and mouth disease (HFMD), a common rash illness in children and infants. There is no effective antiviral treatment for severe EV7I infections and no vaccine is available. The objectives of this study were to design and construct a DNA vaccine against Enterovirus 7 I using the viral capsid protein (VPI) gene of EV7I and to verify the functionality of the DNA vaccine in vitro and in vivo.
\end{abstract}

Methods: The VPI gene of EV7I from two local outbreak isolates were amplified using PCR and then inserted into a eukaryotic expression vector, pVAXI. The $3.9 \mathrm{~kb}$ recombinant constructs were transformed into competent $E$. coli cells and the positive clones were screened and selected using PCR analysis, restriction digestion analysis and DNA sequencing. The constructs were then tested for protein expression in Vero cells. Subsequently, in the in vivo studies, female Balb/c mice were immunized with the DNA vaccine constructs. Enzyme Linked Immunosorbent Assay (ELISA) and virus neutralizing assay were performed to detect the presence of anti-VPI IgG in mice and its neutralizing effect against the EV7I.

Results: The PVAXI vector was successfully cloned with the VPI gene from each of the isolate (S2/86/I and 4I0/4) in the correct orientation and in-frame. The DNA vaccine constructs with the VPI gene were shown to be expressed in a cell-free in vitro expression system. The VPI protein was successfully expressed in the mammalian cell line and was detected using RT-PCR, Indirect Immunofluorescence Assay (IFA) and western blotting. The anti-VPI lgG levels in mice immunized with the DNA vaccine constructs increased after the first booster but declined following the second booster. The anti-VPI IgG in the mice immunized with the DNA vaccine constructs exhibited neutralising activity against EV7I.

Conclusion: The promising results obtained in the present study have prompted further testing to improve the expression and immunogenicity of this potential EV7I DNA vaccine. 


\section{Background}

Enterovirus 71 (EV71) belongs to the genus of enteroviruses from the family Picornaviridae. It possesses a single stranded RNA genome of approximately 7500 nucleotides of positive polarity, which is encapsulated in a capsid containing 60 copies of each of the four structural proteins, VP1 through VP4 [1]. The antigenic diversity among the enteroviruses is caused by variations within capsid proteins VP1 to VP3, but neutralization epitopes are most densely clustered on VP1 [2].

Enterovirus 71, along with coxsackievirus A16 (CA16), is a major causative viral agent responsible for large outbreaks of hand, foot and mouth disease (HFMD), a common rash illness in children and infants. EV71 is thought to spread by contact with fecal contaminated materials. Infection by the virus is often asymptomatic or may manifest as mild self-limiting illness which is often characterized by the presence of characteristic lesions on the palms, soles and oral mucosa. EV71 and CA16 are genetically closely related. However, unlike CA16 that is more limited in its pathogenicity to HFMD, EV71 is also associated with severe complications involving the central nervous system (CNS) such as aseptic meningitis, encephalitis and poliomyelitis-like paralysis [3,4].

Since the first report of EV71 infection which occurred in California in 1969 [5], world-wide reports of outbreaks have followed. The neurovirulence of EV71 first came to attention in 1975 in Bulgaria when 44 people died of a polio-like disease [6]. Epidemics of EV71 causing CNS diseases subsequently occurred in New York, Australia, Europe and Asia [7-10]. An unusual epidemic of HFMD complicated by fatal myocarditis and pulmonary edema occurred in Malaysia in 1997, and EV71 had been implicated as the etiology of the outbreak [11]. Thirty-one children in Sarawak, Malaysia and four children in Peninsular Malaysia succumbed to the infection within hours of admission to the hospitals [12]. The largest EV71 epidemic reported to date occurred from April to December of 1998 in Taiwan in which a variety of clinical manifestations were observed. These included HFMD, encephalitis, meningitis, herpangina and poliomyelitits-like paralysis. In this outbreak, more than 90,000 children infected with HFMD were reported. Among these patients, more than 320 children were hospitalized with suspected meningitis, encephalitis, or acute flaccid paralysis, and at least 55 died, suggesting neurovirulence of the pathogen [13].

There is no effective antiviral treatment for severe EV71 infections and no vaccine is available. Thus, the only current means to prevent EV71 infection is through avoidance of contact between infected and susceptible individuals [14]. Since no effective antiviral agents are available, the need for an effective EV71 vaccine is urgent to immunize the public before an outbreak occurs. A formalin-inactivated EV71 vaccine was developed in response to the Bulgarian epidemic in $1975[6,15]$ but was not used to control the epidemic and has not been used since. Thus, no data on the efficacy of the Bulgarian vaccine is available. Recently, several candidates of EV71 vaccines using different approaches are being investigated. These include formalin-inactivated whole virus vaccine, DNA vaccine and recombinant protein vaccine. These vaccine constructs remain promising vaccine strategies that require further refinement, thus further study and development are required [16-18].

In this study, a DNA vaccine encoding the VP1 gene of EV71 was designed and constructed. This vaccine candidate was tested in vitro for expression of VP1 protein in mammalian cell culture and followed by in vivo testing of the ability for the protein to be expressed and to elicit an immune response in mice.

\section{Materials and methods}

\section{I Construction and validation of DNA vaccine}

The VP1 gene of EV71 isolate 410/4 (genotype B4) and EV71 isolate S2/86/1 (genotype B4) which have been cloned into $\mathrm{pCR}^{\circledR}$ Blunt Vector (Zero Blunt ${ }^{\mathrm{TM}}$ PCR Cloning Kit, Invitrogen) were provided by Prof. Mary Jane Cardosa, Universiti Malaysia Sarawak (UNIMAS). The VP1 gene of both isolates was amplified by polymerase chain reaction (PCR). A forward primer 5'-GATCTGCAGGCCACCATGGGGGATAGAGTGGCAGATG-3' and a reverse primer 5'-GAAGCGGCCGCCTAAAGGGTAGTAATGGCAGTACG-3' were used to amplify the VP1 gene of EV71 isolate 410/4, whereas a forward primer 5'GATCTGCAGGCCACCATGGGAGATAGAGCGGCAGATG-3' and a reverse primer 5'-GAAGCGGCCGCCTAAAGGGTAGTAATGGCAGTACG-3' were used to amplify the VP1 gene of EV71 isolate S2/86/1. The Pst I site and Not I site (underlined) were included in the forward and reverse primers, respectively for the purpose of cloning. The PCR temperature profile included denaturation at $95^{\circ} \mathrm{C}$ for $5 \mathrm{~min}$, followed by 30 cycles of denaturation at $95^{\circ} \mathrm{C}$ for $1 \mathrm{~min}$, annealing at $62^{\circ} \mathrm{C}$ and extension at $72^{\circ} \mathrm{C}$ for $1 \mathrm{~min} 20 \mathrm{~s}$, followed by $10 \mathrm{~min}$ of heating at $72^{\circ} \mathrm{C}$. The PCR products were then purified and subjected to automated sequencing for confirmation. Subsequently, the amplified VP1 gene was digested with Pst I and Not I and ligated with the pVAX1 vector. The pVAX1/VP1 plasmid was transformed into One Shot ${ }^{\circledR}$ TOP 10 Chemically Competent Cells (Invitrogen).

\subsection{Detection of cell-free in vitro expression of VPI protein} The Transcend ${ }^{\mathrm{TM}}$ Non-Radioactive Translation Detection Systems (Promega, U.S.A.) was used to detect the VP1 proteins synthesized in vitro. Biotinylated lysine residues are incorporated into nascent proteins during translation in a 
cell-free single-tube, coupled transcription/translation reaction for eukaryotic in vitro protein expression. After running SDS-PAGE and electroblotting, the biotinylated VP1 proteins can be visualised by binding to StreptavidinHorseradish Peroxidase, followed by chemiluminescent detection.

\subsection{In-vitro protein expression in eukaryotic cells}

Vero cells (ATCC CCL-81) were cultured in RPMI 1640 with $10 \%$ fetal calf serum added until growth reach $80 \%$ confluence. Lipofectamine ${ }^{\mathrm{TM}} 2000$ (Invitrogen) was used to transfect the DNA vaccine constructs following the manufacturer's instruction. The negative control experiment was performed using the backbone vector, pVAX1. The transfected cells were incubated at $37^{\circ} \mathrm{C}$ in a $5 \% \mathrm{CO}_{2}$ incubator for 48 hours before detection of VP1 gene expression was carried out.

\subsection{Detection of VPI mRNA}

The expression of VP1 gene was determined by detecting the presence of VP1 mRNA using RT-PCR. Isolation of total RNA from the transfected cultured cells was performed using SV Total RNA Isolation System (Promega). RETROscript $^{\mathrm{TM}}$ kit (Ambion) was used to reverse transcribe the extracted RNA into its complementary DNA sequence (cDNA). The cDNA was used as template for the amplification of VP1 gene using PCR method as described in 2.1. The PCR products were subjected to agarose gel electrophoresis to detect the presence of VP1 gene.

\subsection{Indirect Immunofluorescence Assay (IFA)}

Light Diagnostic Enterovirus 71 Monoclonal Antibody (Chemicon International, CA, USA) was used to detect the VP1 protein expressed in cell culture using an indirect immunofluorescence assay (IFA). Briefly, the transfected cells were removed after 48 hours of incubation and resuspended in PBS to make cell spots on microscope slides. The slides were fixed in chilled $\left(2-8^{\circ} \mathrm{C}\right)$ acetone for 10 minutes. Sufficient Enterovirus 71 Monoclonal Antibody was added to cover the cells on the slides and incubated at $37^{\circ} \mathrm{C}$ for 30 minutes in an incubator. The slides were washed gently with PBS and then added with sufficient anti-mouse IgG: FITC (Chemicon International, CA, USA) to cover the cells. Subsequently, the slides were mounted with cover slips and examined using a fluorescence microscope (DMRA2, Leica).

\subsection{Western blot}

After 72 hours of incubation, the transfected cells were harvested and protein isolation was carried out using Mammalian Protein Extraction Reagent (Pierce, U.S.A.). The protein samples were loaded onto a discontinuous SDS-polyarylamide gel with 5\% stacking gel and $12.5 \%$ separating gel. Electrophoresis was performed using MiniPROTEAN $^{\circledR}$ III Electrophoresis Cell (Bio-Rad, U.S.A.). Sub- sequently, the protein bands were electrophoretically transferred from the SDS-polyacrylamide gel to PVDF membrane using a Mini Trans-Blot ${ }^{\circledR}$ Electrophoretic Transfer Cell (Bio-Rad, U.S.A.). The VP1 protein was detected using rabbit anti-EV71 polyclonal antibody and alkaline phosphatase conjugate chicken anti rabbit secondary antibody (Chemicon, U.S.A.).

\subsection{DNA vaccination of BALB/c mice}

Ethical approval to work with animals was obtained from the Animal Care and Use Committee (ACUC), Faculty of Medicine and Health Sciences, UPM. Female Balb/c mice aged between 6-8 weeks with 19-21 gm weight were divided in groups of 6 and were immunised by intramuscular injection with each of the DNA vaccine constructs: pVAX1/VP1-4, pVAX1/VP1-S or pEGFPN-1/VP1 (EV71 VP1-expresing vector which was provided by Prof. Dr. Sazaly Abu Bakar, University of Malaya and served as a control). The mice were injected with $100 \mu$ of the plasmid DNA solution in phosphate buffered saline (PBS) at a concentration of $100 \mu \mathrm{g}$ per mouse. The two negative control groups, each with 6 mice, were injected with the backbone vector pVAX1 (100 $\mu$ g per mouse) and PBS (100 $\mu \mathrm{l}$ per mouse). The animals were given food and water ad lib. The mice in each group were given booster injections at 14 and 28 days post-immunisation. Blood samples were collected from the mice by cardiac puncture at day 0 , day 14, day 28 and day 42 of experiment.

\subsection{Enzyme Linked Immunosorbent Assay (ELISA)}

To detect the presence of anti-VP1 IgG in the sera of immunised mice, Enzyme Linked Immunosorbent Assay (ELISA) was performed using ELISA Reagent Kit (Chemicon International, U.S.A.) and 96-well microtiter plates coated with VP1 fusion protein and S. tag protein (negative control). Optical density (O.D.) was read at $450 \mathrm{~nm}$ using an ELISA reader. The adjusted O.D. of each sample was calculated by subtracting the mean O.D. of the control well from the mean O.D. of VP1 antigen well. Statistical analysis of the adjusted O.D. between the different groups immunized with DNA vaccines and negative controls was performed using one-way ANOVA test.

\subsection{Virus neutralizing assay}

The virus neutralisation test was performed to assess the ability of the mice serum to neutralise the live enterovirus 71. A positive serum from an EV71-infected child (provided by Prof. Dr. Sazaly Abu Bakar, University Malaya) was used as a positive serum control in this test. The test was carried out using the pooled mice sera of each group (pVAX1/VP1-S, pVAX1/VP1-4, pVAX1 and PBS) collected on day 14 . Vero cells were seeded in 96-well plates at a density of $1 \times 105$ cells/well in RPMI supplemented with $10 \%$ FBS and incubated overnight. To perform the neutralisation test, the mice sera samples were first incubated 
at $56^{\circ} \mathrm{C}$ for 30 minutes to inactivate the complement. A two-fold serial dilution (from 1:2 to 1:64) was carried out by diluting the test mice serum with RPMI medium without FBS. Subsequently, $80 \mu \mathrm{l}$ of each diluted test serum sample was added with $80 \mu \mathrm{l}$ of $1 \times 10^{3}$ p.f.u. of live EV71 (1:1 ratio) and incubated for 1 hour at $37^{\circ} \mathrm{C}$. All the tests were performed in triplicates. Then, the Vero cells were washed with $1 \times$ PBS and incubated with $50 \mu \mathrm{l}$ inoculum of test serum-virus mixture per well at room temperature for 1 hour. Virus control wells were included as negative controls in the test where the cells were incubated with only live virus that have not been treated with any serum. After incubation, the cells were added with $200 \mu \mathrm{l}$ of RPMI supplemented with 5\% FBS per well and incubated in cell culture $\mathrm{CO}_{2}$ incubator at $37^{\circ} \mathrm{C}$ with $5 \% \mathrm{CO}_{2}$ for 3 days. The cytopathic effect (CPE) of cells and the number of plaques formed were monitored under an inverted tissue culture microscope (Olympus CK40, Japan). The titre was read as the highest dilution that resulted in more than 50\% CPE.

\section{Results}

\section{I Construction of DNA vaccine}

The amplification of VP1 gene for both isolates produced a 923 bp band as shown in Figure 1. Each amplicon (VP1 gene) had been designed to include the Pst I site and Not I site at both ends to facilitate cloning into expression vector, pVAX1 (Invitrogen, U.S.A.). The PCR products were purified using QIAquick Gel Extraction Kit (Qiagen, Germany) and sent for sequence analysis. The sequencing results confirmed that the amplicons are the VP1 gene of EV71.

The VP1 gene was successfully cloned into the eukaryotic expression vector, $\mathrm{pVAX} 1$ and transformed into One Shot ${ }^{\circledR}$ TOP 10 Chemically Competent Cells (Invitrogen). The

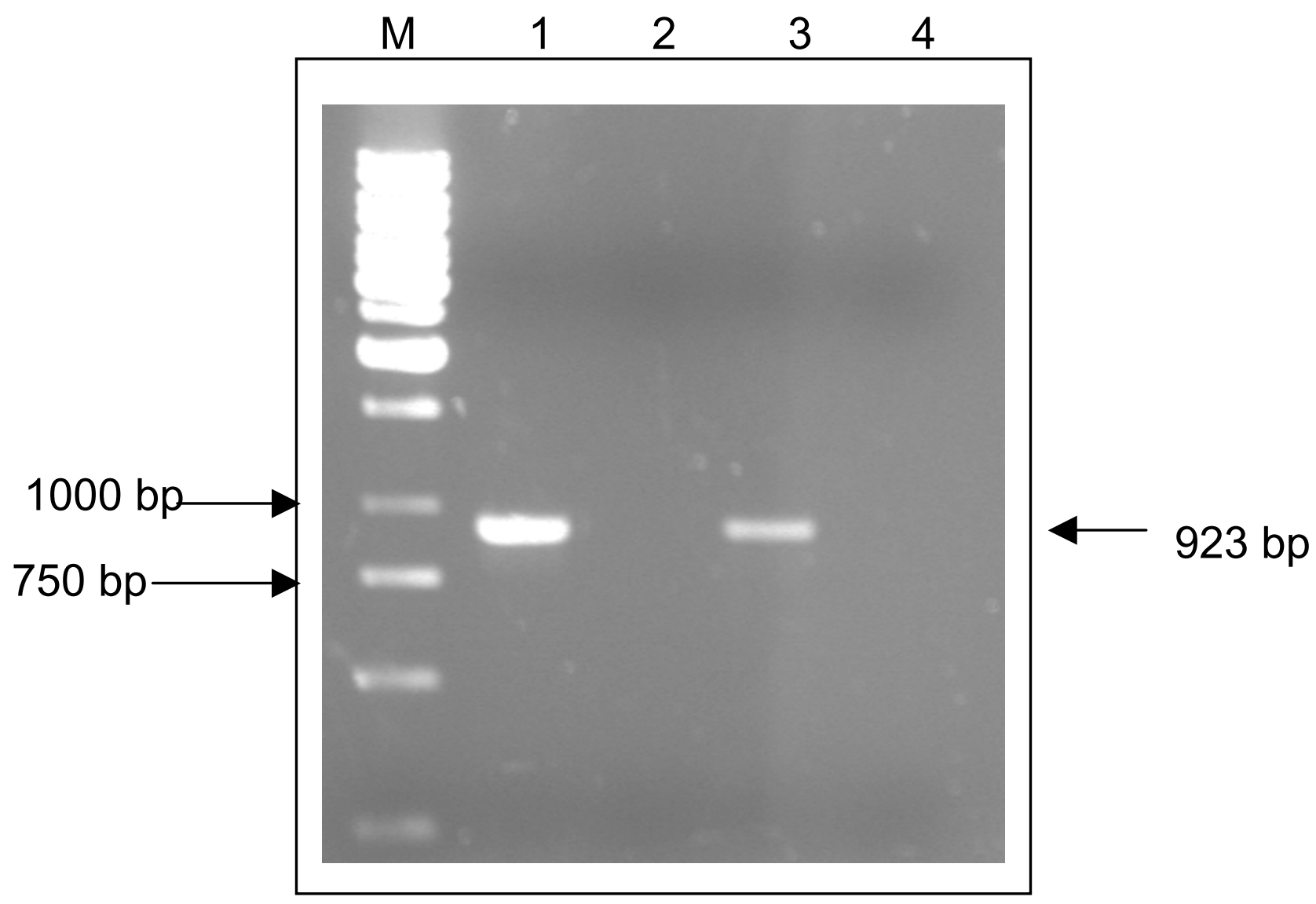

Figure I

Amplification of VPI genes of EV7 I isolate S2/86/I and isolate 4I0/4 by PCR. Lane M shows a I kb molecular marker (Fermentas). Lane I and lane 3 each shows a band of size 923 bp, which represent the PCR product of VPI gene of EV7I isolate S2/86/I and isolate 4I0/4, respectively. Lane 2 and lane 4 which show no band of PCR product are PCR negative controls that used water as template. 


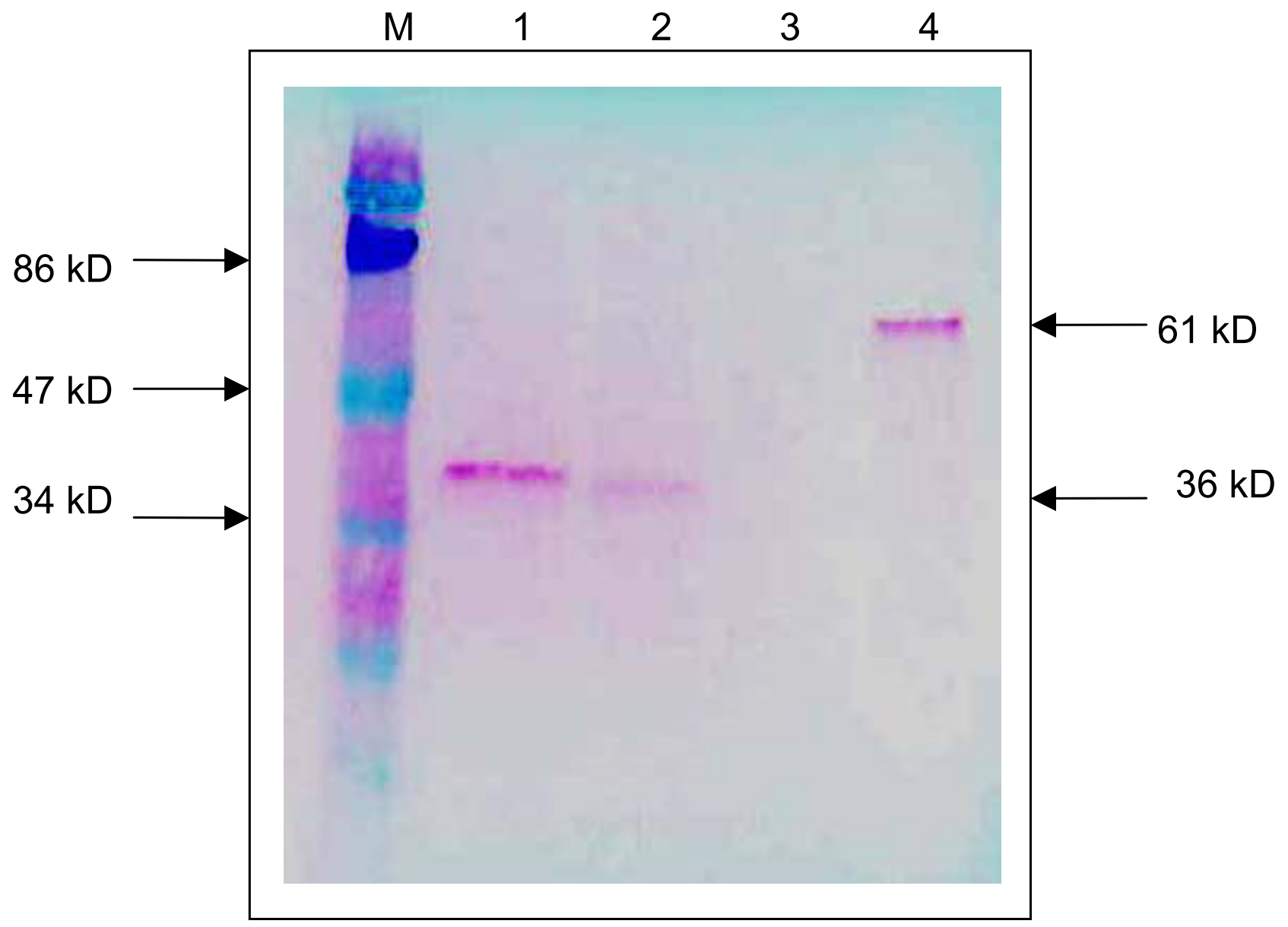

\begin{abstract}
Figure 2

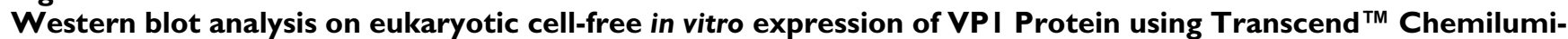
nescent Translation Detection Systems (Promega, U.S.A.). Lane M shows a prestained protein molecular weight marker (Fermentas, Lithuania). Lane I to lane 4 represent the eukaryotic cell-free in vitro transcription/translation reactions of pVAXI/VPI-S, pVAXIVPI-4, pVAXI and Luciferase T7 control DNA respectively. Lane I and lane 2 each shows a band of size $36 \mathrm{kD}$, indicating the translated VPI protein. Lane 3 shows no band of translation product with using backbone vector pVAXI alone. Lane 4 shows a band of size $6 \mathrm{I} \mathrm{kD}$, indicating the translated luciferase protein, which serve as a positive control for the eukaryotic cell-free in vitro expression reactions.
\end{abstract}

positive clones that carried the pVAX1/VP1 DNA vaccine were screened and selected using PCR and restriction digestion analysis. The desired constructs were further confirmed by automated DNA sequencing. The pVAX1 vector that was successfully cloned with VP1 gene of each EV71 isolate S2/86/1 and isolate 410/4, in the correct orientation and in frame were designated as pVAX1/VP1-S and pVAX1/VP1-4, respectively.

The DNA vaccine constructs were verified for VP1 gene expression using a cell-free in vitro expression system, TNT $^{\circledast}$ Quick Coupled Transcription/Translation System (Promega. U.S.A.). The biotinylated lysine residues were incorporated into the VP1 protein during translation. Using the chemiluminescent detection method with streptavidin-alkaline phosphatase in Western blotting, a protein band with a size of $36 \mathrm{kD}$ was obtained in each transcription/translation reaction of pVAX1/VP1-S and pVAX1/VP1-4 which indicated the translated VP1 protein (Figure 2, lanes 1 and 2). There was no protein band observed in the reaction sample of backbone vector pVAX1 (Figure 2, lane 3) since it did not contain any coding sequence. 


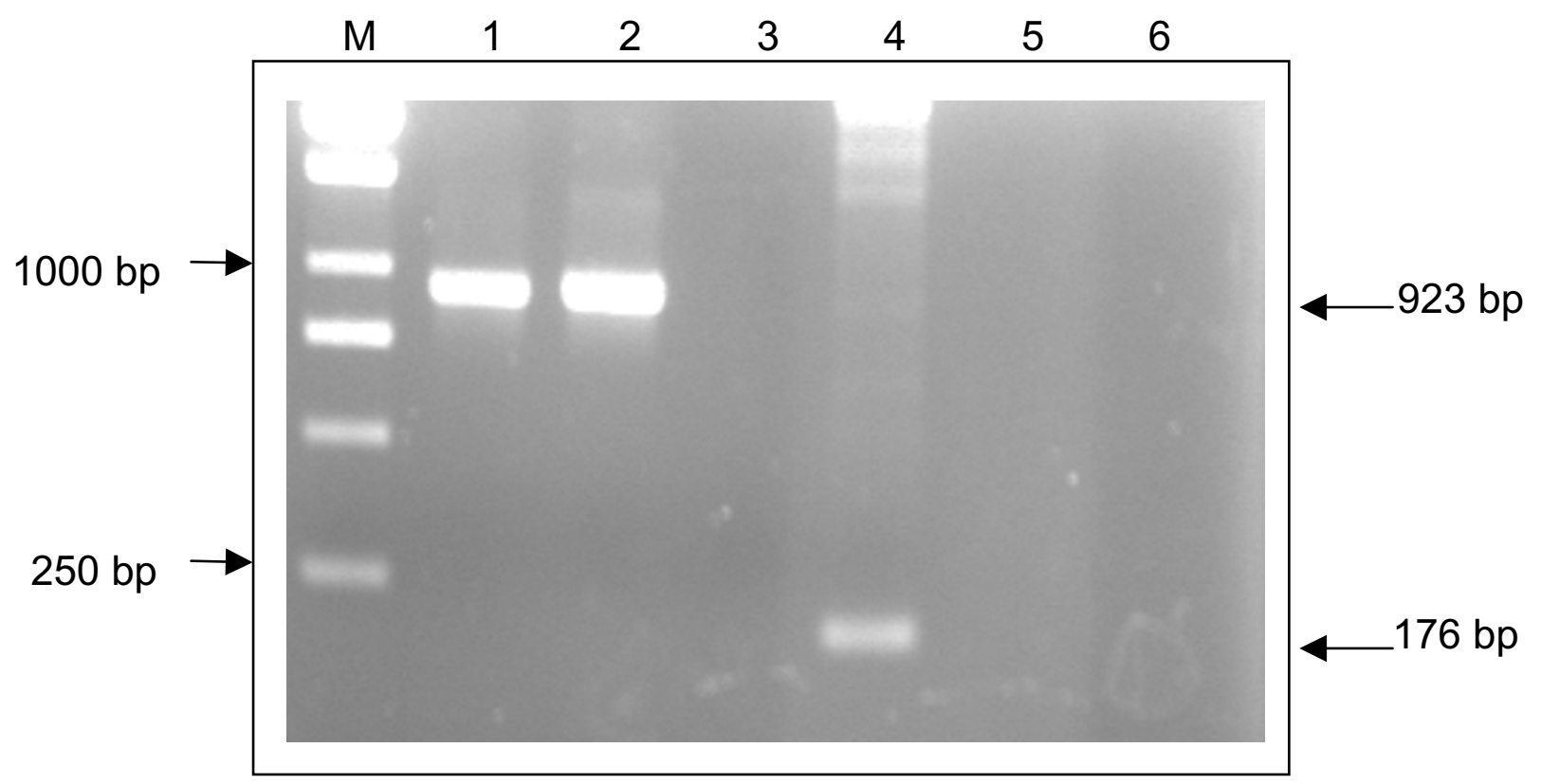

\section{Figure 3}

Amplification of VPI gene by RT-PCR. Lane M shows a I kb molecular weight marker (Fermentas, Lithuania). Lane I and lane 2 each shows a band of size 923 bp, indicating the amplified VPI gene from extracted mRNA of Vero cells transfected with PVAXI/VPI-S and pVAXI/VPI-4 respectively. Lane 3 shows no RT-PCR product amplified from extracted mRNA of Vero cells transfected with backbone vector PVAXI alone, which serve as a negative control. Lane 4 shows the PCR product of size I76 bp when backbone vector pVAXI was amplified using T7 forward primer and BGH reverse primer. Lane 5 and lane 6 show no PCR product generated from the extracted mRNA of Vero cells transfected with pVAXI/VPI-S and pVAXI/VPI-4 respectively, when using $\mathrm{T} 7$ forward primer and $\mathrm{BGH}$ reverse primer.

\subsection{Detection of VPI mRNA using RT-PCR}

A PCR product of expected size 923 bp that represents the VP1 gene was obtained using cDNA derived from Vero cells transfected with pVAX1/VP1-S and pVAX1/VP1-4 (Figure 3, lanes 1 and 2, respectively). To eliminate the possibility that the VP1 PCR product was produced because of plasmid DNA contamination, T7 forward primer and BGH reverse primer were used to amplify the cDNA derived from cells transfected with pVAX1/VP1. No product was amplified (Figure 3, lanes 5 and 6) since the T7 forward and BGH reverse priming sites were only found on pVAX1 vector but not the cDNA that was derived from the transfected Vero cells. Plasmid DNA pVAX1 was used as a control for this PCR reaction using T7 and BGH primers. A PCR product of $176 \mathrm{bp}$ was obtained (Figure 3, lane 4), indicating that this primer pair could produce an amplicon from the plasmid DNA pVAX1. No PCR product was obtained using cDNA derived from cells transfected with control plasmid, the backbone vector pVAX1 (Figure 3, lane 3).

\subsection{Indirect Immunofluorescence Assay (IFA)}

Enterovirus 71 positive and negative control slides (Chemicon, U.S.A.) were included to assure proper performance of the test. The positive control slide showed cells exhibiting apple-green fluorescence (Figure 4a). Apple-green fluorescence signals were detected in the cells transfected with pVAX1/VP1-S and pVAX1/VP1-4 (Figure $4 \mathrm{~b}$ and $4 \mathrm{c}$, respectively). The cells transfected with the backbone vector pVAX1, which served as a negative control did not exhibit any fluorescence (Figure 4d).

\subsection{Western blot}

A band of $36 \mathrm{kD}$ was visualised in protein extracts from cells transfected with pVAX1/VP1-S and pVAX1/VP1-4, which represents the VP1 protein (Figure 5, lanes 1 and 2, respectively). No visible band parallel to the VP1 protein $(36 \mathrm{kD})$ was observed in the cells transfected with backbone vector pVAX1 (Figure 5, lane 3) and non-transfected vero cells (Figure 5, lane 4), which indicated the absence of VP1 protein in these two samples that served as negative controls. Extracted protein of enterovirus 71 that 
a)

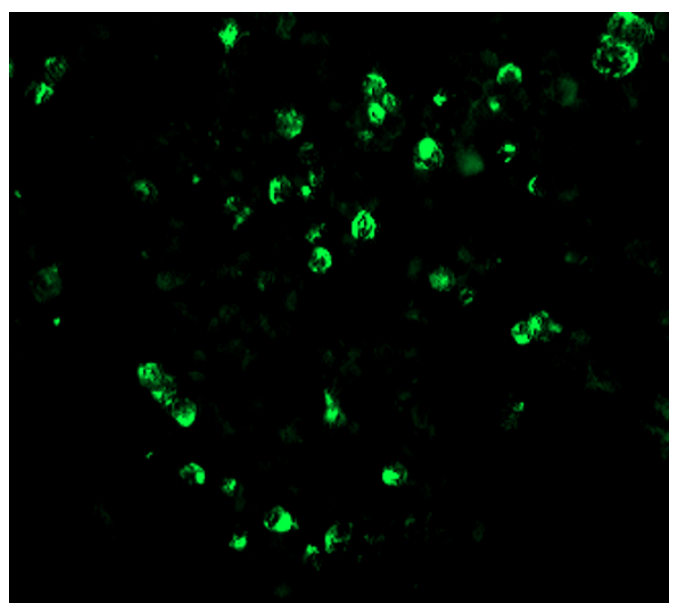

c)

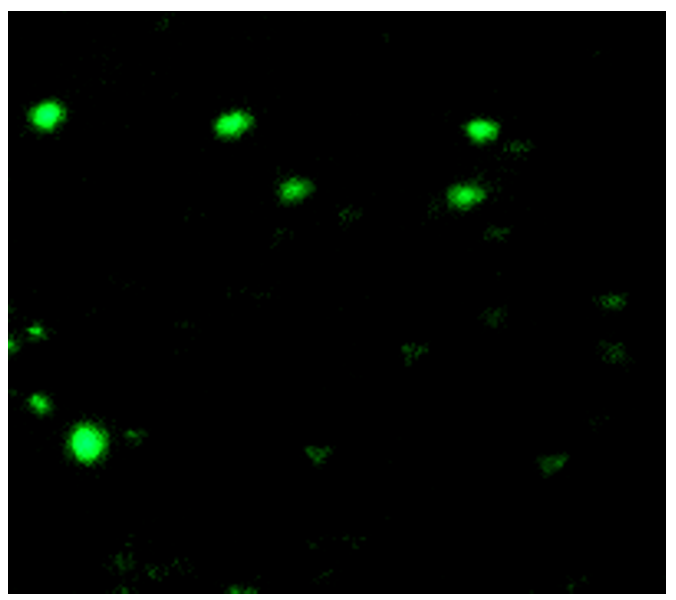

b)

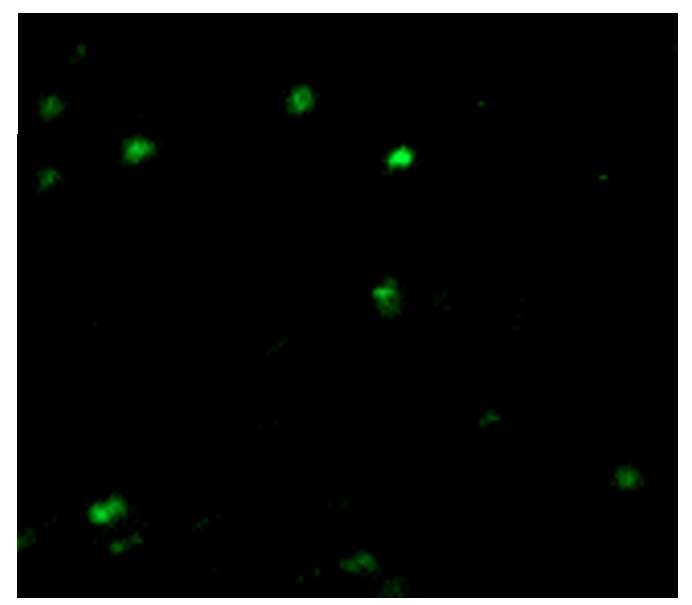

d)

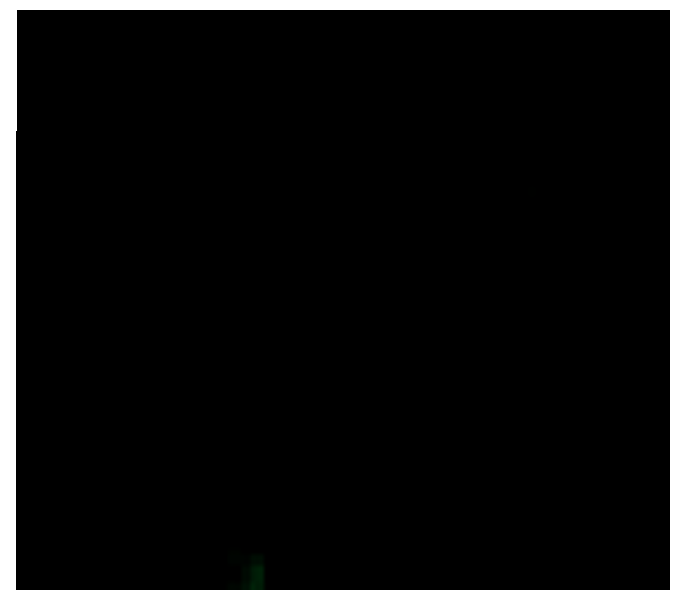

Figure 4

Detection of VPI protein using indirect immunofluorescence assay (IFA). Expression of VPI protein in transfected vero cells at 48 hours post-transfection was detected by using indirect immunofluorescence assay (IFA). Figure a) shows the EV $7 /$ positive control slide. Figure b) and c) show vero cells transfected with PVAXI/VPI-S and PVAXI/VPI-4, respectively. Figure d) shows vero cells transfected with PVAXI.

served as a positive control produced a $36 \mathrm{kD}$ band of VP1 protein (Figure 5, lane 5).

\subsection{Enzyme Linked Immunosorbent Assay (ELISA)}

The anti-VP1 IgG elicited in immunised mice sera on day 0 , day 14, day 28 and day 42 post-vaccination was measured using ELISA. There was no significant difference $(\mathrm{p}>$ $0.05)$ between the anti-VP1 IgG responses elicited in all the mice groups before vaccination, i.e. on day 0 (Figure $6 a)$. The anti-VP1 IgG elicited by pVAX1/VP1-S and pVAX1/VP1-4 increased to a very significant level ( $\mathrm{p}<$
0.001 ) on day 14 when compared to the negative control groups (Figure 6b). After the first booster, the anti-VP1 IgG in these two groups continually increased to a level with the highest OD value (Figure 6c) but subsequently declined after the second booster although the level was still statistically significant $(\mathrm{p}<0.01)$ compared to negative control groups (Figure $6 \mathrm{~d}$ ).

There was no significant increase ( $p>0.05)$ in anti-VP1 IgG level of mice immunized with pEGFPN1/VP1 on day 14 when compared with the level in negative control 


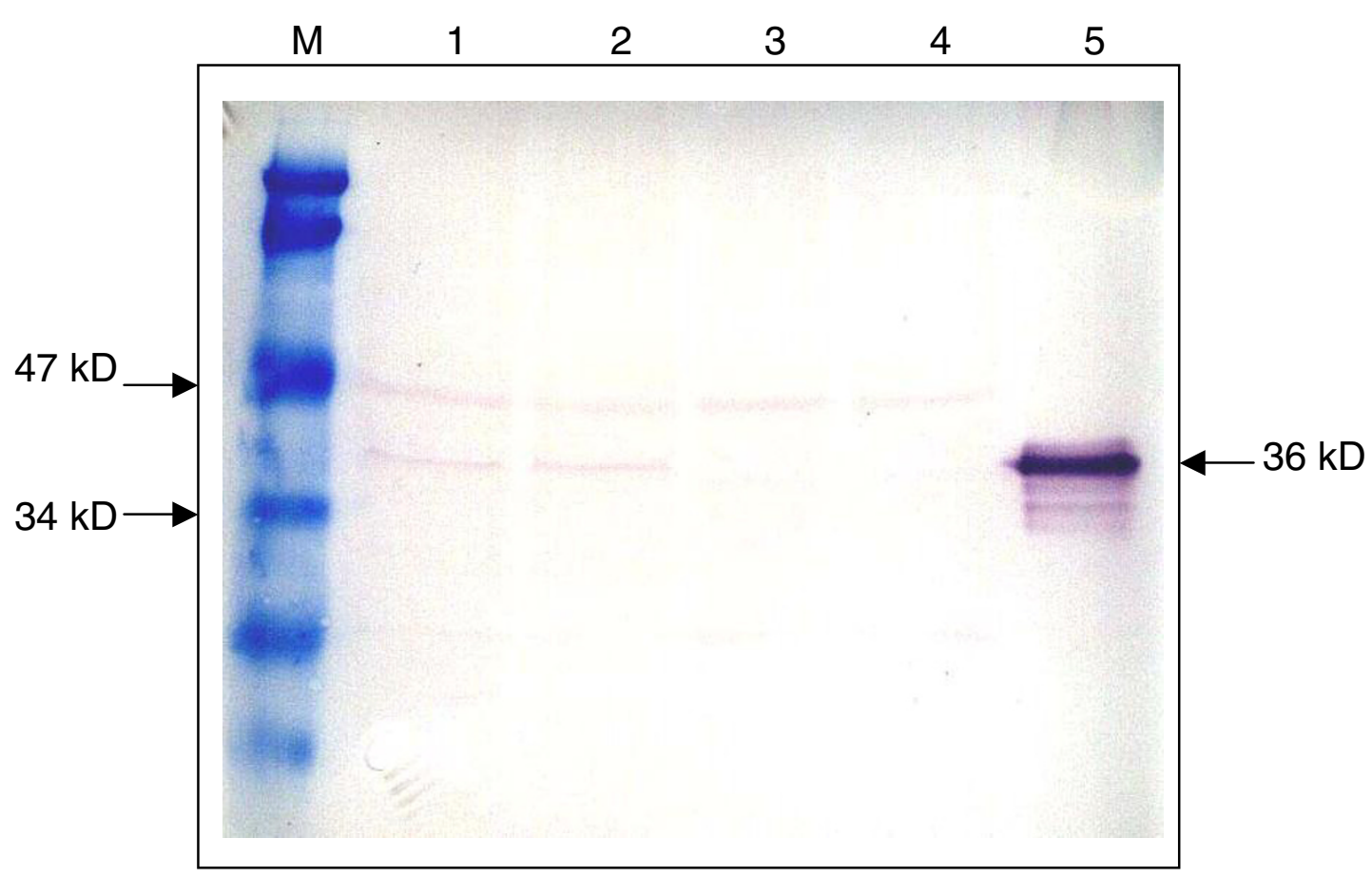

Figure 5

Western blot analysis of transfected vero cells at 72 hours post transfection using rabbit anti-VP I polyclonal antibody. Lane $M$ shows a prestained protein molecular weight marker (Fermentas, Lithuania). Lane I and lane 2 each shows a band of size $36 \mathrm{kD}$, which represent the expressed VPI protein in Vero cells transfected with pVAXI/VPI-S and pVAXI/ VPI-4 respectively. Lane 3 and lane 4 represent Vero cells transfected with backbone vector pVAXI alone and non-transfected Vero cells respectively, show no band of size $36 \mathrm{kD}$, indicating the absence of VPI protein. Lane 5 represents the extracted protein of EV 7I, shows a band of size $36 \mathrm{kD}$, which serve as a positive control.

groups (Figure 6b). The anti-VP1 IgG level of this group rose after the first booster, but it was not statistically significant ( $p>0.05$ ) when compared to the negative control groups (Figure 6c). The level dropped following the second booster (Figure 6d).

Overall, the anti-VP1 IgG level in all the three DNA vaccine groups (pVAX1/VP1-S, pVAX1/VP1-4 and pEGFPN1/ VP1) increased after the first booster but declined following the second booster (Figure 7). A statistically significant difference between the level of anti-VP1 IgG elicited in DNA vaccine groups (pVAX1/VP1-S and pVAX1/VP1-4) and the negative control groups (pVAX1 and PBS) at day $14(\mathrm{p}<0.001)$, day $28(\mathrm{p}<0.01)$ and day $42(\mathrm{p}<0.01)$ was observed. However, the pEGFPN1/VP1 group did not show any statistically significant difference $(p>0.05)$ compared to the negative control groups.

\subsection{Virus neutralisation assay}

The virus neutralisation test was used to evaluate the ability of the DNA vaccine constructs, pVAX1/VP1-S and pVAX1/VP1-4 to elicit a neutralising antibody response. By adding live virus to the test serum, the presence of neutralising antibody in the test serum will bind to the virus. If this occurs, no virus residue will remain to infect the Vero cells. On the other hand, if there is no neutralising antibody in the test serum, no antibody will bind to the virus and the virus will then infect the cells, resulting in cytopathic effect (CPE). It has been reported that cells infected with EV71 exhibited a CPE with morphological changes, including rounding up, shrinkage, cytoplasmic blebbing, nuclear condensation and detachment from the culture dish, indicative of apoptotic cells [19]. Similar CPE was observed in this study.

After 3 days of incubation, all the virus control wells showed 100\% CPE (Figure 8c). Meanwhile, the positive EV71 infected human serum resulted in almost $100 \%$ 


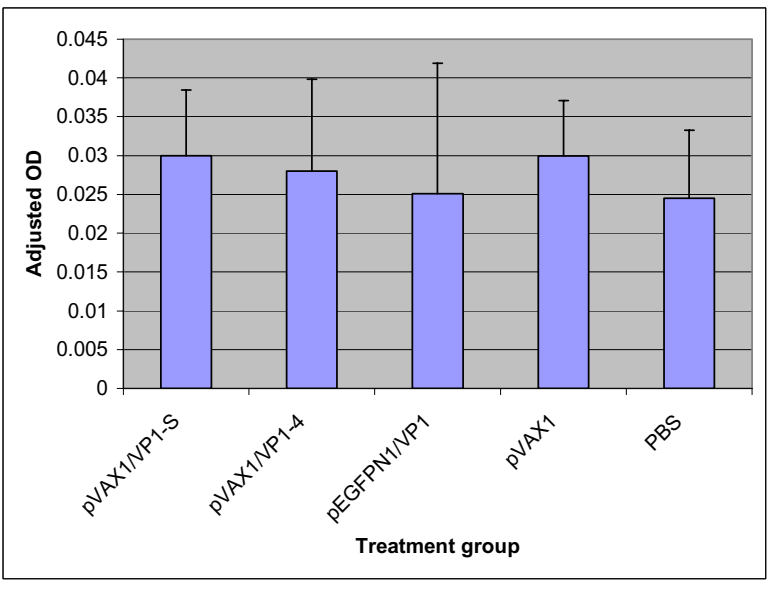

a) Day 0

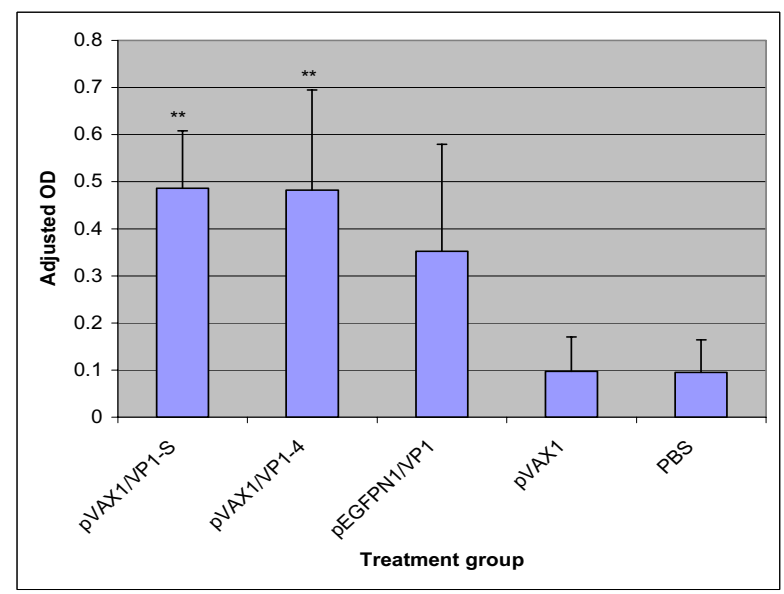

c) Day 28

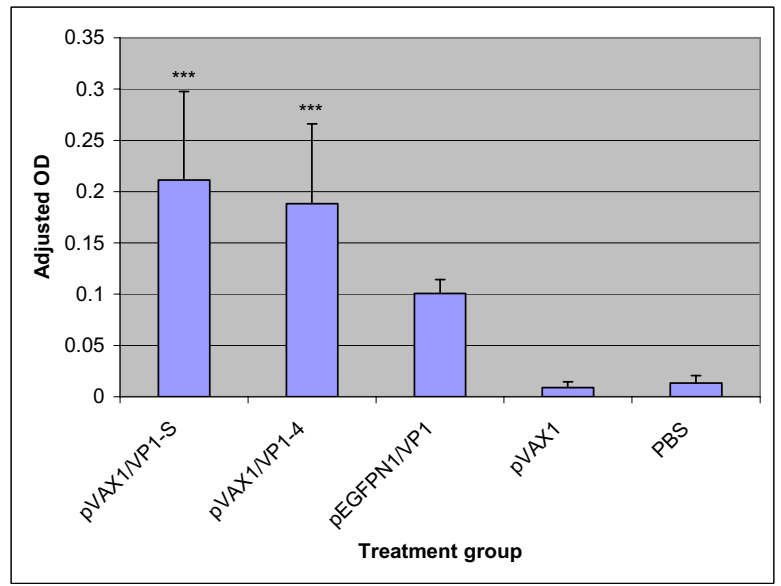

b) Day 14

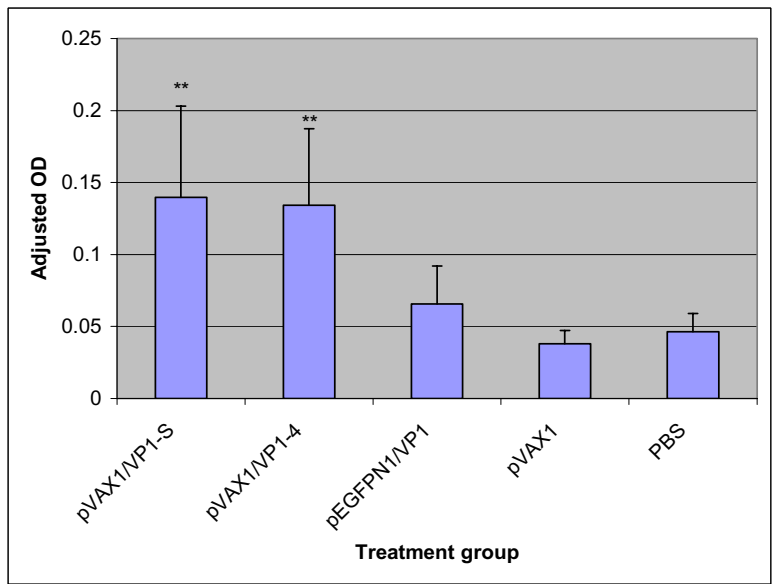

d) Day 42

\section{Figure 6}

Adjusted OD at $450 \mathrm{~nm}$ of ELISA for anti-VPI IgG of mice serum collected at different days post-immunization at I:50 dilution.

neutralisation at the dilution of $1: 8$ to $1: 64$, where no sign of CPE was observed, hence demonstrating the neutralising effect (Figure 8f). At the dilution of $1: 2$ and 1:4, the human serum had caused cell death without signs of CPE where it might be due to the side effect of high serum concentration.

The sera of DNA vaccine groups (pVAX1/VP1-S and pVAX1/VP1-4) had resulted in approximately 50\% CPE at a dilution of $1: 32$ (Figure $8 \mathrm{~d}$ and $8 \mathrm{e}$ ). Only about $15 \%$ and 10\% CPE was observed at the dilution of 1:16 and $1: 8$, respectively. Obviously, the positive EV71 infected human serum antibody reduced EV71 infectivity much more effectively, compared with the sera of animals immunized with DNA vaccines. The sera of negative control groups, pVAX1 (Figure 8a) and PBS (Figure 8b), showed no neutralization activity where almost $100 \%$ $\mathrm{CPE}$ was observed at all dilutions. The highest dilution of mice sera that resulted in more than $50 \%$ CPE is shown in Figure 9.

\section{Discussion}

In the present study, the DNA vaccine encoding the VP1 gene of Enterovirus 71 (EV71) was designed and constructed. These DNA vaccine constructs were verified and tested for in vitro expression of VP1 gene in Vero cell line. 


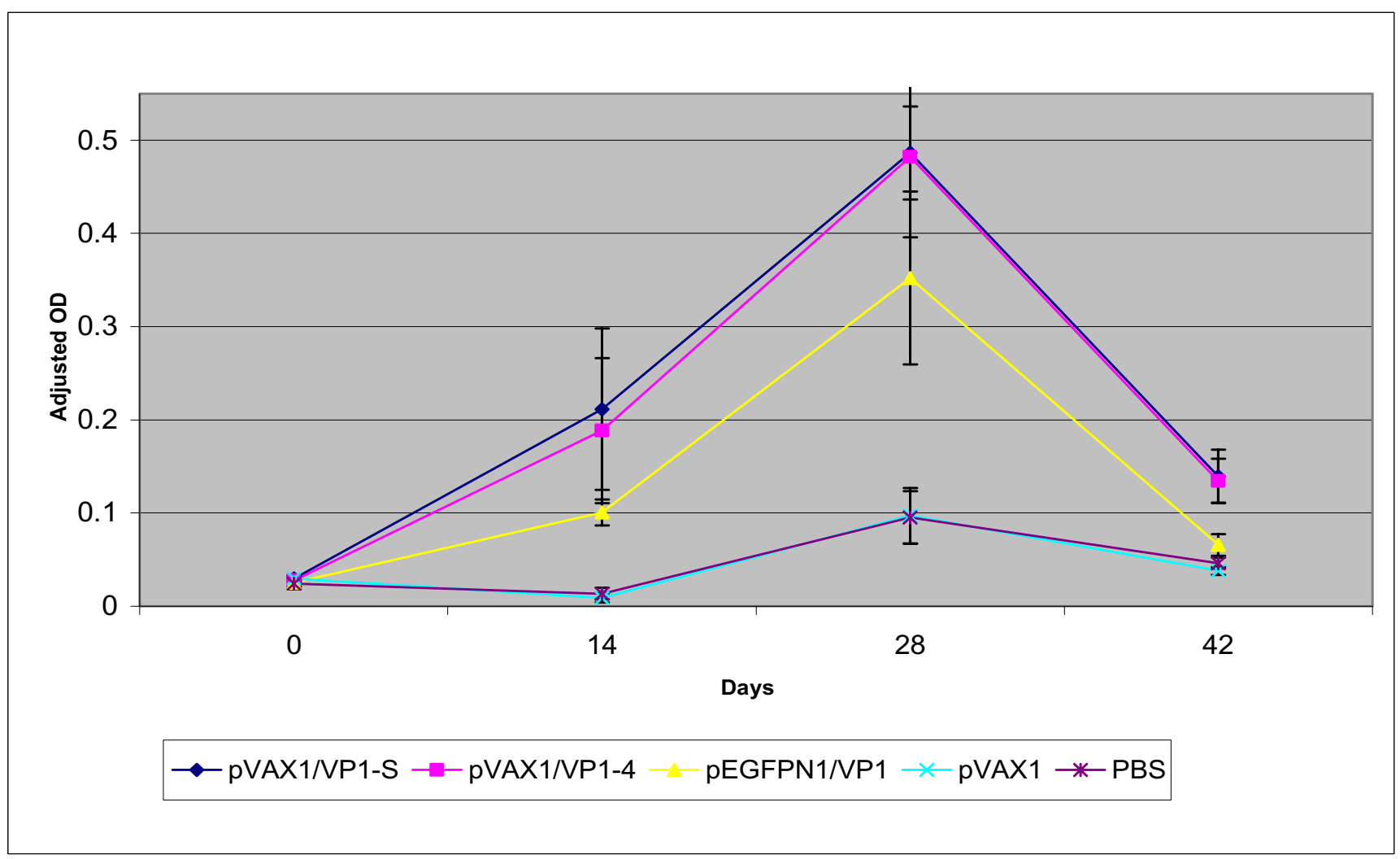

Figure 7

Adjusted OD at $450 \mathrm{~nm}$ of ELISA for anti-VPI IgG of mice serum collected at different time points at I:50 dilution.

VP1 mRNA was detected in transfected cell culture by RTPCR whereas the presence of VP1 protein was confirmed by indirect immunofluorescence assay (IFA) and westernblotting. VP1 mRNA in transfected Vero cells was detected by reverse transcription-polymerase chain reaction (RTPCR) at 48 hours post-transfection. However, the presence of VP1 mRNA is just a qualitative data and it cannot reveal the level of VP1 expression, as the copy number of target transcript was not determined. Real-time PCR analysis can be conducted in order to quantify the in vitro expression level of VP1 gene in cell culture if necessary. The VP1 protein expressed in cell culture was successfully detected using Indirect Immunofluorescence Assay (IFA) and Western blot method at 48 hours and 72 hours posttransfection, respectively. The presence of VP1 protein could not be detected with Western blotting at time points earlier than 72 hours post-transfection, where this could be due to low level of expression and thus insufficient quantity of protein that can be detected. Comparatively, Western blotting using colorimetric method is not as sensitive as IFA, which utilises the aid of an optical instrument (fluorescence microscope) for detection of target protein. There are many possible reasons for low expression of an antigen, such as toxicity, poor codon usage, or
mRNA structure instability. It is also possible that the antigenic protein is unstable and rapidly degraded [20]. The successful in vitro expression implies that the constructs were able to direct VP1 protein synthesis correctly in eukaryotic cells, thus confirming the functionality of the constructs.

In order to assess the immune responses to DNA vaccine, immunisation of female Balb/c mice was carried out using intramuscular injection of the naked plasmid. Following DNA immunisation, the antigenic proteins expressed from plasmids especially for viral antigens seem to be expressed, folded and assembled in the same manner as when they are expressed during a natural viral infection. As a result, the antigens are genuine with all the conformational epitopes required for protection being expressed $[21,22]$.

One of the major barriers to the development of an EV71 vaccine is the lack of a suitable animal model for the testing of vaccine immunogenicity and efficacy. Laboratory mice are only susceptible to EV71 infection in the first 4 days of life and become completely resistant by 6 days of age $[18,23]$. EV71 infection caused no apparent clinical 
a)

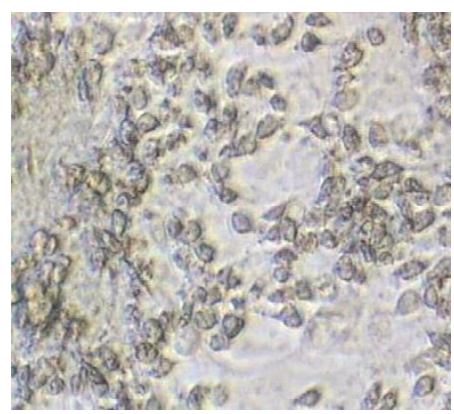

c)

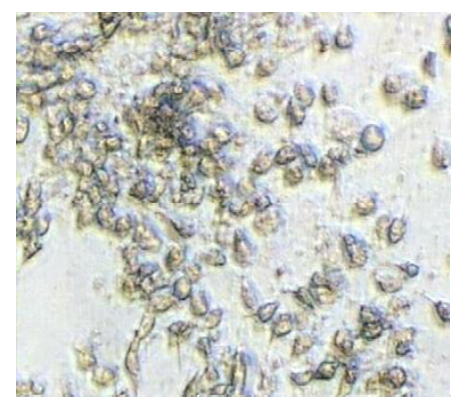

e)

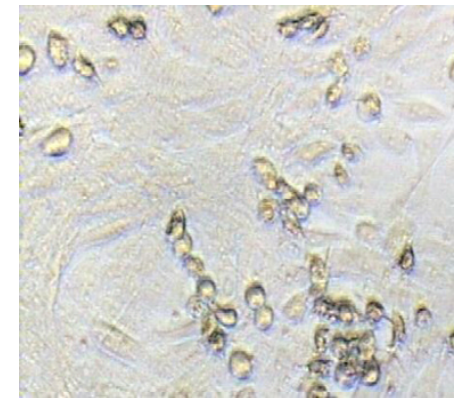

g)

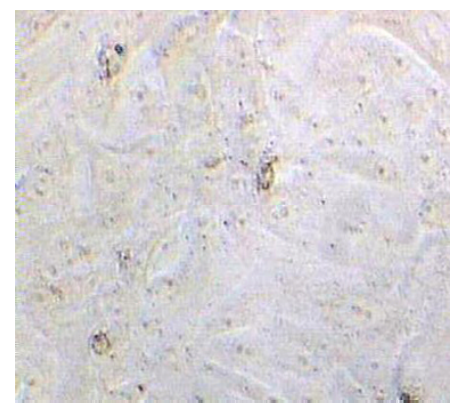

b)

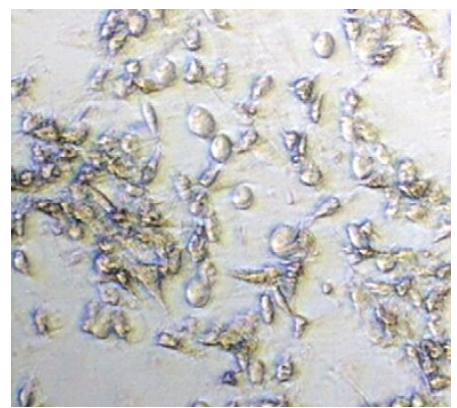

d)

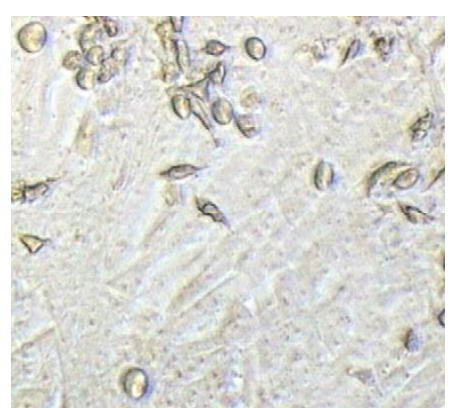

f)

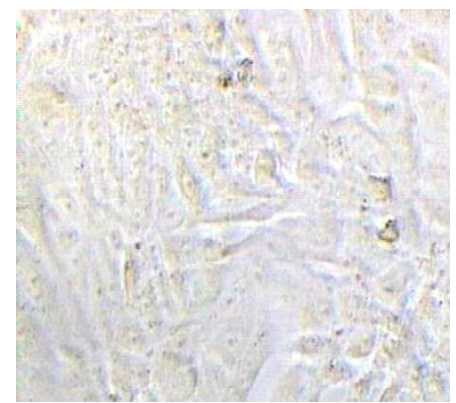

\section{Figure 8}

Virus neutralisation test of immunized mice seraon day I4. The neutralising activity of immunised mice sera against EV7I on day 14 was evaluated by virus neutralisation test using Vero cells. Figure $8 \mathrm{a}$ ) and $8 \mathrm{~b}$ ) show almost $100 \%$ of CPE in Vero cells resulted by sera of mice immunized with PVAXI and PBS (negative) respectively. Figure $8 \mathrm{c}$ ) represents the virus control well with almost $100 \%$ CPE observed. Figure $8 \mathrm{~d}$ ) and $8 \mathrm{e}$ ) showed the neutralizing activity of sera of mice immunized with PVAXI/VPI-S and PVAXI/VPI-4 respectively, where approximately $50 \%$ CPE was observed. Figure $8 f$ ) showed almost $100 \%$ neutralization of EV7I-infected human positive serum where no CPE was observed. Figure 8g) represents the normal Vero cells that are not infected with EV7I. All the dilution of serum samples in Figure 8a) to 8f) was at I:32 and microscopy examinations were carried out at $100 \times$ magnification. Arrows indicate the CPE. 


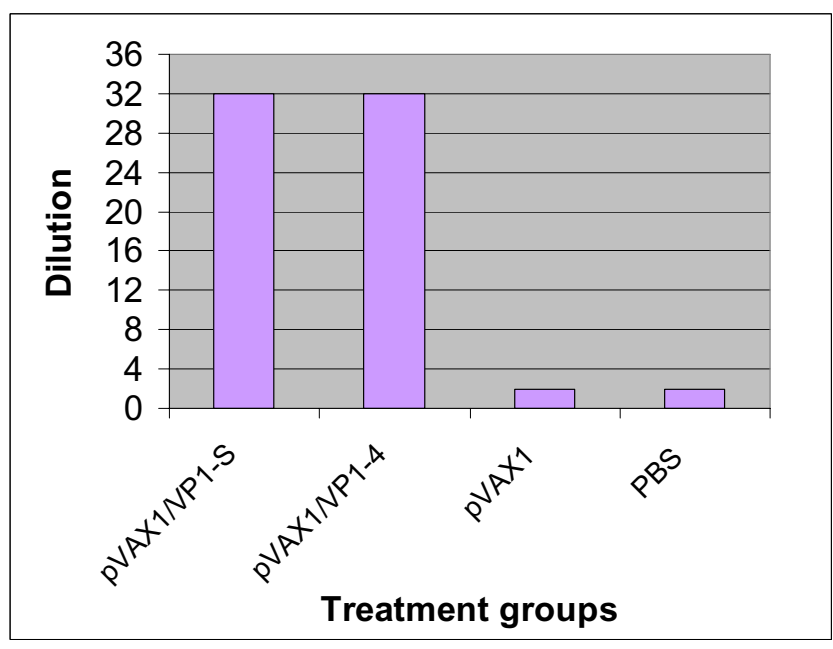

\section{Figure 9}

The highest dilution of mice sera that resulted inmore than $\mathbf{5 0 \%}$ CPE. The sera of DNA vaccine groups (pVAXI/VPI-S and pVAXI/VPI-4) had resulted in approximately $50 \%$ CPE at a dilution of I:32. Almost 100\% CPE was observed in the sera of negative control groups (PVAXI and PBS) at the dilution of $1: 2$ and the subsequent dilutions.

symptoms in all strains of adult mice tested, including BALB/c, C3H, ICR, CD28 knock-out, and TNF- $\alpha$ receptor knock-out mice [16]. Therefore, if further studies were to be carried out in order to assess the protection against lethal EV71 infection provided by the antibody elicited following DNA vaccination, newborn mice have to be challenged with enterovirus 71 and then followed by passive transfer of maternal antibody from immunised dams to the newborn mice.

In the present study, the results of ELISA have confirmed the immunogenicity of DNA vaccine constructs in eliciting immune response in vivo with the presence of specific anti-VP1 IgG in mice sera. Studies have shown that expression of genes from plasmids following injection into muscles is optimal at 7-14 days post-injection [24]. In this study, anti-VP1 IgG elicited by pVAX1/VP1-S and pVAX1/ VP1-4 increased to a very significant level on day 14 after the first dose of injection. Following the first booster, the anti-VP1 IgG in these two groups continued to increase to a level with the highest OD value (Figure 6) but subsequently declined after the second booster. The decline of IgG levels observed in this study might have been accompanied by an increase in cytolitic T cells. Tanghe et al. [25] demonstrated that the antibody levels in mice immunised with tuberculosis DNA vaccine decreased after the second booster injection while an increase in IFN- $\gamma$ and IL-2 levels was detected. This observation showed a shift towards the cellular immune response, which may provide an explanation to the decline of anti-VP1 IgG levels observed in the present study. However, this has to be confirmed by further investigation.

From the results of the virus neutralisation assay, the antiVP1 IgG in the mice immunised with DNA vaccine constructs exhibited neutralising activity against EV71. However, the neutralising effect of EV71-infected human positive serum was demonstrated to be much higher compared with the sera of animals immunised with DNA vaccines. The possible explanation for this might be the immune system of mice immunised with DNA vaccine was only exposed to the antigenic epitopes that are found in VP1 protein of EV71 while the EV71-infected human had been exposed to all the various antigenic epitopes of the whole EV71 virus particle. Therefore, the neutralising antibodies produced by human immune system are able to identify the wide range of various antigenic epitopes of EV71 and thus possess higher neutralising effect. Another possible reason could be that the confirmation of the protein synthesized by the plasmids may differ from that in the live virus particles. Therefore, minor differences in the confirmation of the antigenic epitopes could result in different neutralisation titres [26]. In this study, only mice sera of day 14 post-immunisation (after a single dose of vaccination) were tested for the neutralising activity, so there is no further data to show the neutralisation titre after the first and second booster vaccination. However, studies have shown that neutralising antibodies were developed after a first single-dose of DNA vaccination with the neutralisation titre elevated and persisted for an extended interval following booster injections [27-29]. Wu et al. (16) had reported that the neutralisation titre of DNA vaccinated mice was still detectable at 32 weeks post-immunisation and it also maintained a titre similar to the one that immunised with inactivated virus.

pEGFPN1/VP1 which was provided by Prof. Dr. Sazaly Abu Bakar (University Malaya) served as a positive control in the vaccination experiment of the present study. This construct has been shown to express VP1 protein in mice after vaccination. The anti-VP1 IgG level of this group did not show any statistically significant difference compared to the negative control groups. It might be due to the fact that the pEGFPN1 is not an expression vector that is specifically designed for DNA vaccination use, such as the pVAX1 vector. Hence, pEGFPN1/VP1 is not as efficient as pVAX1/VP1-S and pVAX1/VP1-4 in eliciting immune response in mice.

Development of transgenic mice expressing the appropriate human receptor molecule(s) for enterovirus 71 would be the best and promising approach in order to understand the pathogenesis of enterovirus encephalitis and to test the candidate vaccines. This approach has been extremely successful for poliovirus [30]. Since the receptor 
for EV71 remains unknown, identification of the EV71 receptor is a major priority in vaccine research, as it will allow the development of a transgenic mouse model for studies of EV71 pathogenesis and vaccine efficacy.

\section{Conclusion}

Overall, this study has given promising results on genetic immunisation with DNA vaccine encoding VP1 gene of EV71. With further study and improvement, use of the DNA vaccine might be a potential vaccine strategy against EV71.

\section{Acknowledgements}

We would like to thank Prof. Mary Jane Cardosa from Universiti Malaysia Sarawak (UNIMAS) for kindly providing us the VPI gene of EV7I isolate 410/4 (genotype B4) and EV7I isolate S2/86/I (genotype B4) which have been cloned into $\mathrm{PCR}^{\circledR}$ Blunt Vector (Zero Blunt ${ }^{\mathrm{TM}} \mathrm{PCR}$ Cloning Kit, Invitrogen). We would also like to thank the Ministry of Science, Technology and Innovation, Malaysia for providing the IRPA Grant (06-02-09-100IPROOI).

\section{References}

I. Muir P, Kammerer U, Korn K, Mulders MN, Poyry T, Weissbrich B, Kandolf R, Cleator GM, van Loon AM: Molecular typing of enteroviruses: current status and future requirements. Clin Microbiol Rev 1998, I I :202-227.

2. Rueckert RR: Picornaviruses and their replication. In Virology Edited by: Fields BN, Knipe DM. Lippincott-Raven, New York; 1990:507-548

3. Alexander JP, Baden L, Pallansch MA, Anderson LJ: Enterovirus infections and neurologic disease - United States, I977-9 I. Infect Dis 1994, 1 69:905-908.

4. Melnick JL: Enterovirus type 7 I infections: a variedclinical pattern sometimes mimicking paralytic poliomyelitis. Rev Infect Dis 1984, 6(Suppl):S387-S390.

5. Schmidt NJ, Lennette $\mathrm{EH}, \mathrm{Ho} \mathrm{HH}$ : An apparently new enterovirus isolated from patients with disease of the central nervous system. J Infect Dis 1974, I 29:304-309.

6. Chumakov M, Voroshilova M, Shindarov L, Lavrova L, Gracheva L, Koroleva G, Vasilenko S, Brodvarova I, Nikolova M, Gyurova S, Gacheva M, Mitov G, Ninov N, Tsylka E, Robinson I, Frolova M, Bashkirtsev V, Martiyanova L, Rodin V: Enterovirus $7 \mathrm{I}$ isolated from cases of epidemic poliomyelitis-like disease in Bulgaria. Arch Virol 1979, 60:329-340.

7. Blomberg J, Lycke E, Ahlfors K, Johnsson T, Wolontis S, von Zeipel G: New enterovirus type associated with aseptic meningitis and/or hand, foot and mouth disease. Lancet 1974, 2: II 2.

8. Gilbert GL, Dickson KE, Waters MJ, Kennett ML, Land SA, Sneddon $M$ : Outbreak of enterovirus $7 \mathrm{I}$ in Victoria, Australia, with a high incidence of neurologic involvement. Pediatr Infect Dis J 1988, 7:484-488.

9. Nagy G, Takatsy S, Kukan E, Mihaly I, Domok I: Virological diagnosis of enterovirus 7 I infections: Experiences gained during an epidemic of acute CNS diseases in Hungary in 1978. Arch Virol | 982, 7 |:2 | 7-227.

10. Samuda GM, Chang WK, Yeung CY, Tang PS: Monoplegiacaused by enterovirus $7 \mathrm{I}$ infection: an outbreak in Hong Kong. Pediatr Infect Dis J 1987, 6:206-208.

II. Lum LCS, Wong KT, Lam SK, Chua KB, Goh AYT: Neurogenic pulmonary oedema and enterovirus $7 \mathrm{I}$ encephalomyelitis. Lancet 1998, 352:1391.

12. AbuBakar S, Chee HY, Al-Kobaisi MF, Xiaoshan J, Chua KB, Lam SK: Identification of enterovirus 7 I isolates from an outbreak of hand, foot and mouth disease with fatal cases of encephalomyelitis in Malaysia. Virus Res 1999, 61:1-9.

13. Chang LY, Huang YC, Lin TY: Fulminant neurogenic pulmonary oedema with hand, foot and mouth disease. Lancet 1998 , 352:367-368.
14. McMinn PC: An Overview of the evolution of enterovirus7 I and its clinical and public health significance. FEMS Microbiol Rev 2002, 26:91-107.

15. Shindarov LM, Chumakov MP, Voroshilova MK, Bojinov S, Vasilenko SM, Kirov ID, Kamenov E, Leshchinskaya EV, Mitov G, Robinson IA, Sivchev S, Staikov S: Epidemiological, clinical and pathomorphological characteristics of epidemic poliomyelitis-like disease caused by enterovirus 7I. J Hyg Epidemiol Microbiol Immunol 1979, 23:284-295.

16. Wu CN, Lin YC, Cathy Y, Liao NS, Shih SR, Ho MS: Protection against lethal enterovirus $7 \mathrm{I}$ infection in newborn mice by passive immunization with subunit VPI vaccines and inactivated virus. Vaccine 2002, 20:895-904.

17. Liao HT, Hung KL: Neurologic involvement in an outbreakof enterovirus 7 I infection: A hospital-based study. Acta Paediatr Taiwan 2001, 42:27-32.

18. Yu CK, Chen CC, Chen CL, Wang JR, Liu CC, Yan JJ, Su IJ: Neutralizing antibody provided protection against Enterovirus type 7 I lethal challenge in neonatal mice. J Biomed Sci 2000, 7:523-528.

19. Chan YF, AbuBakar S: Enterovirus 7 I infection induces apoptosis in Vero cells. Malaysian J Pathol 2003, 25(I):29-35.

20. Ertl PF, Thomsen LL: Technical issues in construction of nucleic acid vaccines. Methods 2003, 3 I: 199-206.

21. Montgomery DL, Ulmer JB, Donnely JJ, Liu MA: DNAVaccines. Pharmacol Ther 1997, 74(2): 195-205.

22. Babiuk LA, Pontarollo R, Babiuk S, Loehr B, van Drunen Littel-vanden Hurk S: Induction of immune responses by DNA vaccines in large animals. Vaccine 2003, 2 I:649-658.

23. Roberts GBS, Boyd JF: The histopathology of enterovirus infections in new-born mice. J Infect 1987, I 5:45-56.

24. Manthorpe M, Comefert-Jensen F, Hartikka J, Felgner J, Rundell A, Margalith $M$, Dwarki V: Gene therapy by intramuscular injection of plasmid DNA: studies on firefly luciferase gene expression in mice. Hum Gene Ther 1993, 4:419-431.

25. Tanghe A, Denis O, Lamvrecht B, Motte V, van den Berg T, Huygen $\mathrm{K}$ : Tuberculosis DNA vaccine encoding Ag85A is immunogenic and protective when administered by intramuscular needle injection but not by epidermal gene gun bombardment. Infect Immun 2000, 68:3854-3860.

26. Kaur R, Sachdeva G, Vrati S: Plasmid DNA immunizationagainst Japanese Encephalitis Virus: Immunogenicity of membraneanchored and secretory envelope protein. J Infect Dis 2002 , I85: I- I2.

27. Caselli E, Boni M, Di Luca D, Salvatori D, Vita A, Cassai E: A combined bovine herpesvirus I gB-gD DNA vaccine induces immune response in mice. Comp Immunol Microbiol Infect Dis 2005, 28:155-166.

28. Guo H, Liu Z, Sun S, Bao H, Chen Y, Liu X, Xie Q: Immune response in guinea pigs vaccinated with DNA vaccine of footand-mouth disease virus O/China99. Vaccine 2005, 23:3236-3242.

29. Lodmell DL, Parnell MJ, Weyhrich JT, Ewalt LC: Canine rabies DNA vaccination: a single-dose intradermal injection into ear pinnae elicits elevated and persistent levels of neutralizing antibody. Vaccine 2003, 2 I:3998-4002.

30. Horie H, Koike S, Kurata T, Sato-Yoshida Y, Ise I, Ota Y, Abe S, Hioke K, Kato H, Taya C, Nomura T, Hashizume S, Yonekawa H, Nomoto A: Transgenic mice carrying the human poliovirus receptor: new animal model for the study of poliovirus neurovirulence. J Virol 1994, 68:68I-688. 